\title{
Expansão Canavieira e Ocupação Formal em Empresas Sucroalcooleiras do Centro-Sul do Brasil, entre 2007 e 2009
}

\author{
José Giacomo Baccarin ${ }^{1}$ \\ José Jorge Gebara² \\ Júlio Cesar Borges Júnior
}

Resumo: Considerando-se a região Centro-Sul do Brasil e com base nos dados do Ministério do Trabalho e Emprego e do Ministério da Agricultura, Pecuária e Abastecimento, comparou-se a evolução da produção sucroalcooleira com o número e tipos de pessoas formalmente ocupadas em empresas do setor, de 2007 a 2009. Nas empresas dedicadas ao cultivo da cana-de-açúcar, o número de pessoas ocupadas caiu nesses três anos, enquanto aumentava nas empresas dedicadas à produção de açúcar e etanol. Quanto às categorias de ocupação, constatou-se aumento no número de pessoas ocupadas em atividades industriais, administrativas, de apoio ou não sucroalcooleiras, enquanto diminuíam as pessoas ocupadas na agricultura. Neste caso, houve redução dos trabalhadores canavieiros não qualificados e crescimento dos trabalhadores da mecanização agrícola, fatos associados à intensificação da adoção da colheita mecânica de cana-de-açúcar. Não ocorreu mudança expressiva na sazonalidade de emprego dos trabalhadores canavieiros não qualificados, que permaneceu muito alta. $\mathrm{O}$ aumento mais intenso da produção do que do número de pessoas ocupadas refletiu em indicadores de produtividade, com crescimento da relação da produção de cana-de-açúcar, tanto com o total de pessoas ocupadas, quanto com o número de trabalhadores canavieiros não qualificados. Também foi constatada redução significativa na relação desse grupo de trabalhadores com a área colhida com cana-de-açúcar.

Palavras-chave: ocupação sucroalcooleira, empresas sucroalcooleiras, produtividade do trabalho, Centro-Sul, Brasil.

1 Professor doutor do Departamento de Economia Rural - FCAV/Unesp, Jaboticabal (SP). E-mail: baccarin@fcav.unesp.br

2 Professor Adjunto do Departamento de Economia Rural - FCAV/Unesp. E-mail: jjgebara@reitoria.unesp.br

3 Acadêmico do curso de Administração - Departamento de Economia Rural - FCAV/ Unesp. E-mail: borges_julio28@yahoo.com.br 
494 - Expansão Canavieira e Ocupação Formal em Empresas Sucroalcooleiras do Centro-Sul do Brasil, entre 2007 e 2009

\begin{abstract}
Considering the Central-Southern region in Brazil and based on data from the Ministry of Labor and Employment and the Ministry of Agriculture, Livestock and Supply, the development of sugar and ethanol production has been compared with the number and types of people formally employed by companies in that sector, from 2007 to 2009. In the companies dedicated to the sugarcane planting, the number of employed persons fell in those three years, while it was increasing in companies dedicated to the production of sugar and ethanol. Concerning the occupation category, an increase in the number of persons employed in industrial, administrative, support or not sugar and ethanol activities was found, while the number of persons employed in agriculture was decreasing. In this case, there was a reduction in not qualified sugarcane workers and growth of workers of the agricultural mechanization, facts related to the increase of the adoption of mechanized harvesting of sugarcane. No significant change occurred in seasonal employment of not qualified sugarcane workers, which remained very high. The most expressive increase of the production compared to the number of employed persons reflected in indicators of yield, with growth of the production ratio of the sugarcane as to the total of employed people as to the number of non-qualified sugarcane workers. Moreover, a significant reduction in the ratio of this group of workers with the area harvested with sugarcane was revealed.
\end{abstract}

Key-words: sugarcane occupation, sugar and ethanol companies, labor yield, CentralSouthern, Brazil.

Classificação JEL: J43.

\title{
1. Introdução
}

Na primeira década do século XXI tem-se registrado considerável expansão do setor sucroalcooleiro brasileiro, especialmente no Centro-Sul do País, composto pelas regiões Centro-Oeste, Sudeste e Sul. Assim, a produção de cana-de-açúcar passou de 205,2 milhões de toneladas na safra 2000/01, para 500,2 milhões de toneladas em 2008/09, crescimento de 143,8\%. No mesmo período, a produção de etanol passou de $8.990,3$ milhões de litros para $25.207,3$ milhões de litros, aumento de 180,4\% , enquanto a produção de açúcar crescia 116,8\%, de 12,5 milhões de toneladas para 27,1 milhões (MAPA, 2009).

A expansão setorial também se evidencia quando se analisam os dados do parque industrial sucroalcooleiro. Até o final de 2006, existiam 200 usinas e destilarias cadastradas junto ao Ministério de Agricultura, Pecuária e Abastecimento (Mapa) e localizadas no Centro-Sul do Brasil. Entre janeiro de 2007 e junho de 2010, mais 147 unidades agroindustriais localizadas nessa região foram cadastradas junto ao Mapa (MAPA, 2010). 
A princípio, pode-se supor que esse forte ritmo de crescimento setorial tenha sido acompanhado da elevação da ocupação nas empresas sucroalcooleiras. Contudo, algumas evidências mostram que as mudanças tecnológicas, especialmente nas atividades agrícolas, têm acontecido com tal intensidade, que, pelo menos para algumas categorias de pessoas ocupadas com menor grau de qualificação, o número de postos de trabalho, em vez de aumentar, têm diminuído (BACCARIN e GEBARA, 2010).

Especificamente, tem sido observado que a substituição da colheita manual de cana-de-açúcar previamente queimada pela colheita mecânica com e sem queimar vem ganhando celeridade. Contribuem para isso razões de ordem econômica e gerencial, a edição de legislações prevendo a eliminação gradativa da queimada da cana-de-açúcar (FREDO et al., 2008) e as perspectivas de exportação de etanol para mercados que estabelecem maiores exigências ambientais.

Estimativas apresentadas por Paes (2007) apontam que a área colhida com colhedoras no Centro-Sul passou de 16\% da área total, em 1997, para 34\% em 2006. Dados mais recentes, disponíveis apenas para o estado de São Paulo, indicam que a área de cana-de-açúcar colhida sem queimar passou de 34,2\% na safra 2006/07, para 55,7\% na temporada 2009/104 (AGUIAR et al., 2010).

Além da colheita, realizada entre abril e novembro, nas condições do Centro-Sul, outra operação agrícola em que se observam modificações importantes é o plantio de cana-de-açúcar, realizado, normalmente, nos quatro primeiros meses do ano. Neste caso, já se constata que algumas empresas estão substituindo o plantio manual pelo plantio mecânico. Também aumentou o número de cortes de um mesmo canavial, de uma média de três, comum na década de 70, para uma média superior a seis, atualmente. Ou seja, em uma mesma área de cana-de-açúcar, o plantio tende a se repetir, nos dias atuais, a cada sete anos, contra os quatro anos da década de 70, reduzindo a necessidade de trabalhadores por área de cana-de-açúcar.

As mudanças tecnológicas na lavoura canavieira, além de afetarem o número de pessoas ocupadas em atividades braçais, também podem provocar efeitos na sazonalidade de emprego dessas pessoas ao longo do ano. Pode-se imaginar que, se as mudanças na colheita forem mais intensas que as do plantio, haveria uma tendência de redução da sazonalidade de emprego.

Já nas atividades industriais, no interior das usinas e destilarias, e nas atividades administrativas e de apoio, as mudanças tecnológicas e gerenciais tenderam a ser mais significativas no início dos anos 1990. Neste sentido,

4 A área colhida mecanicamente no estado de São Paulo, certamente, é maior que a área de cana-de-açúcar colhida sem queimar. Uma parte da colheita mecânica se faz após a queima dos canaviais, devido às dificuldades, especialmente de máquinas mais antigas, em operarem com o excesso de palha, característico da lavoura canavieira. Para 2006, Paes (2007) estimava que 27\% da colheita mecânica era feita em área com cana queimada. Atualmente, esse número deve ser menor. 
operações do processamento industrial da cana-de-açúcar foram informatizadas e automatizadas, o mesmo correndo com atividades administrativas, além de se terceirizarem serviços como os de manutenção de máquinas, de limpeza e de segurança.

Atualmente, essas mudanças ocorrem menos abruptamente, sendo possível se supor que, diferente das categorias de pessoas ocupadas em atividades agrícolas com baixa qualificação, o número de pessoas ocupadas em atividades industriais, administrativas e de apoio sucroalcooleiras aumente, ainda que com menor intensidade, acompanhando o crescimento da produção setorial.

\subsection{Objetivos}

Levando-se em conta diferentes tipos de empresas e diferentes categorias ocupacionais, este trabalho pretende analisar como o número de pessoas formalmente ocupadas em empresas sucroalcooleiras do Centro-Sul do Brasil evoluiu entre 2007 e 2009 em face à expansão da produção sucroalcooleira. Especificamente, pretende-se analisar:

a) A evolução da ocupação entre diferentes tipos de empresas sucroalcooleiras;

b) A evolução da ocupação de diferentes categorias profissionais, com destaque para os trabalhadores canavieiros não qualificados;

c) As modificações na sazonalidade de emprego dos trabalhadores canavieiros não qualificados;

d) A evolução de indicadores de produtividade do trabalho na atividade sucroalcooleira.

\section{Metodologia}

Os dados de produção de cana-de-açúcar, açúcar e etanol usados no trabalho foram obtidos junto a publicações da Conab (Companhia Nacional de Abastecimento) e do Ministério da Agricultura, Pecuária e Abastecimento.

Já os dados de ocupação foram obtidos junto aos arquivos do Ministério do Trabalho e Emprego (MTE) do governo federal do Brasil, que registram informações sobre ocupação formal (com carteira de trabalho assinada) prestadas pelas próprias empresas empregadoras ${ }^{5}$.

5 Nas condições prevalecentes no Centro-Sul do Brasil, estimava-se que a ocupação formal representasse $80 \%$ da ocupação total em empresas sucroalcooleiras (MORAES, 2004). Como, de maneira geral, a formalidade de trabalho no Brasil aumentou a partir de 2004, é possível supor que o mesmo tenha se dado com as empresas sucroalcooleiras, aumentando a representatividade de estudo como amostra da ocupação setorial. 
As empresas enviam dois tipos de relatório ao MTE, um com dados de ocupação em 31 de dezembro de cada ano, chamado de Relação Anual de Informações Sociais(Rais). O outroregistra, para cada mês doano, a movimentação (admissão e demissão) das pessoas ocupadas, chamado de Cadastro Geral de Empregados e Desempregados (Caged). A partir das informações da Rais de um ano qualquer, pode-se obter uma estimativa do número de pessoas ocupadas em determinado mês do ano seguinte, agregando-se os números de admissões e demissões registrados até então pelo Caged.

A partir desses dados, primeiramente, fez-se uma análise da ocupação de acordo com o tipo de empresa. Neste sentido, consideraram-se como empresas sucroalcooleiras aquelas classificadas na Rais e no Caged nos seguintes grupos: cultivo da cana-de-açúcar, fabricação do açúcar em bruto, fabricação do açúcar refinado e fabricação de etanol. É preciso observar que essa classificação se estabelece de acordo com a atividade principal que a empresa declara exercer, sendo que uma empresa classificada, por exemplo, como de cultivo da cana-deaçúcar, pode se dedicar também a outras atividades sucroalcooleiras ou mesmo de outros ramos da economia.

Outra observação é que, no Brasil, é grande a integração vertical entre a produção de açúcar e etanol e a produção da cana-de-açúcar. Na safra 2007/08, foi constatado que, nas agroindústrias sucroalcooleiras do Centro-Sul do Brasil, $65,4 \%$ da cana-de-açúcar moída era proveniente de canaviais das próprias usinas ou destilarias e apenas 34,6\% vinham de fornecedores independentes (CONAB, 2008). Assim, pressupõe-se que o número de pessoas ocupadas em atividades agrícolas nas empresas dedicadas à fabricação do açúcar em bruto, fabricação do açúcar refinado ou fabricação de etanol seja significativo, embora menos importante que no caso das empresas dedicadas ao cultivo da cana-de-açúcar.

A análise dos resultados nesse trabalho é feita considerando-se isoladamente o ocorrido em empresas do cultivo da cana-de-açúcar e o ocorrido no conjunto dos outros três tipos de empresas sucroalcooleiras.

Em um segundo momento, analisou-se os tipos de ocupação sucroalcooleira. Para isso, considerou-se o nível de classificação família ocupacional, conforme a Classificação Brasileira de Ocupações $(\mathrm{CBO})^{6}$. Foi constatada a existência de 380

6 A CBO foi instituída pela Portaria Ministerial no 397, em 2002, e tem por finalidade a identificação das ocupações no mercado de trabalho para fins classificatórios junto a registros administrativos e domiciliares. Ela classifica as ocupações em quatro grupos. O Grande Grupo Ocupacional constitui o nível mais agregado da classificação. O subgrupo Ocupacional Principal busca melhorar o equilíbrio hierárquico entre o número de grandes grupos e subgrupos. O subgrupo Ocupacional indica o domínio dos campos profissionais de Famílias Ocupacionais agregadas. A Família Ocupacional contempla 596 grupos de base, que agrupam situações de emprego ou ocupações similares (MTE, 2009). 
famílias ocupacionais nas empresas sucroalcooleiras, de um total de 596 grupos de base registrados na $\mathrm{CBO}^{7}$.

De acordo com a experiência acumulada pelos autores deste trabalho, essas famílias foram organizadas em dois grandes agrupamentos: pessoas ocupadas na agricultura e demais pessoas ocupadas em empresas sucroalcooleiras. Neste, estão incluídas as pessoas ocupadas em atividades industriais, administrativas, de apoio ou mesmo não sucroalcooleiras.

Por sua vez, o agrupamento pessoas ocupadas na agricultura foi subdividido em trabalhadores canavieiros não qualificados, trabalhadores da mecanização agrícola e outras pessoas ocupadas na agricultura. A primeira subdivisão resulta da soma de três famílias ocupacionais, quais sejam trabalhadores agropecuários em geral, trabalhadores de apoio à agricultura e trabalhadores agrícolas na cultura de gramíneas, e entende-se que aí estão incluídos os trabalhadores que se dedicam às atividades que não exigem maior qualificação profissional, como o plantio e o corte de cana-de-açúcar. A segunda subdivisão constitui uma família ocupacional específica da $\mathrm{CBO}$, e a terceira resulta da soma das demais famílias ocupacionais observadas na lavoura canavieira.

Para os trabalhadores canavieiros não qualificados, analisou-se a variação de seu número entre os meses de determinado ano, procurando captar eventuais mudanças na sazonalidade de emprego.

Por fim, foram construídos indicadores que relacionassem o número de pessoas ocupadas com a produção setorial e com a área de cana-de-açúcar, procurando captar mudanças nos índices de produtividade.

\section{Resultados}

Na sequência dos objetivos previamente definidos, a seguir, são analisados os resultados do trabalho.

\subsection{Ocupação por Tipo de Empresas}

Na Tabela 1, são registradas as pessoas ocupadas em empresas do cultivo da cana-de-açúcar. Como já afirmado, espera-se que neste tipo de empresa as ocupações agrícolas sejam mais relevantes. Ao se tomar a média anual, observa-se uma diminuição de 4,2\% no número de pessoas ocupadas entre 2007 e 2008, e de $3,4 \%$ entre 2008 e 2009 .

7 Uma relação das diferentes Famílias Ocupacionais sucroalcooleiras pode ser encontrada em BACCARIN e BARA (2009). 
Tabela 1. Pessoas ocupadas no final do mês em empresas do grupo cultivo da cana-deaçúcar, Centro-Sul do Brasil, 2007 a 2009

\begin{tabular}{cccc}
\hline Mês/Ano & $\mathbf{2 0 0 7}$ & $\mathbf{2 0 0 8}$ & $\mathbf{2 0 0 9}$ \\
\hline Janeiro & 158.166 & 148.854 & 145.755 \\
Fevereiro & 183.652 & 172.715 & 156.160 \\
Março & 207.255 & 190.746 & 188.949 \\
Abril & 235.484 & 226.255 & 219.565 \\
Maio & 257.455 & 240.070 & 228.834 \\
Junho & 258.163 & 243.516 & 229.317 \\
Julho & 252.774 & 241.086 & 227.522 \\
Agosto & 249.637 & 238.126 & 226.826 \\
Setembro & 247.316 & 235.328 & 226.032 \\
Outubro & 239.635 & 230.008 & 224.087 \\
Novembro & 209.922 & 215.313 & 217.100 \\
Dezembro & 136.099 & 143.530 & 148.980 \\
Média do Ano & $\mathbf{2 1 9 . 6 3 0}$ & $\mathbf{2 1 0 . 4 6 2}$ & $\mathbf{2 0 3 . 2 6 1}$ \\
\hline
\end{tabular}

Fonte: MTE (2010).

Tabela 2. Pessoas ocupadas no final do mês em empresas dos grupos fabricação do açúcar em bruto, fabricação do açúcar refinado e fabricação de etanol, Centro-Sul do Brasil, 2007 a 2009

\begin{tabular}{cccc}
\hline Mês/Ano & $\mathbf{2 0 0 7}$ & $\mathbf{2 0 0 8}$ & $\mathbf{2 0 0 9}$ \\
\hline Janeiro & 206.474 & 233.178 & 234.772 \\
Fevereiro & 223.276 & 258.325 & 243.313 \\
Março & 242.973 & 284.856 & 280.771 \\
Abril & 297.270 & 338.064 & 329.077 \\
Maio & 320.752 & 349.858 & 338.910 \\
Junho & 320.656 & 348.720 & 339.161 \\
Julho & 314.769 & 342.672 & 335.369 \\
Agosto & 312.430 & 337.865 & 332.833 \\
Setembro & 309.700 & 336.439 & 331.058 \\
Outubro & 302.899 & 330.092 & 328.066 \\
Novembro & 277.037 & 314.953 & 321.489 \\
Dezembro & 218.904 & 235.110 & 239.747 \\
Média do Ano & $\mathbf{2 7 8 . 9 2 8}$ & 309.177 & 304.548 \\
\hline
\end{tabular}

Fonte: MTE (2010). 
500 - Expansão Canavieira e Ocupação Formal em Empresas Sucroalcooleiras do Centro-Sul do Brasil, entre 2007 e 2009

A Tabela 2 apresenta a ocupação em empresas sucroalcooleiras dedicadas prioritariamente à produção industrial. Entre 2007 e 2008, houve uma expansão considerável de 10,8\% no número de pessoas ocupadas. Tal fato não se repetiu entre 2008 e 2009 , com registro de uma pequena queda, na casa dos $1,5 \%$. Isso pode ser momentâneo, associado ao menor nível de atividade econômica e de investimentos que atingiu a economia brasileira, o que acabou tendo reflexo no setor sucroalcooleiro.

\subsection{Ocupação por Categorias Profissionais}

A Tabela 3 mostra que o número total de pessoas ocupadas em empresas sucroalcooleiras do Centro-Sul passou de 498.562 em 2007, para 519.640 em 2008, e depois se reduziu para 507.808 em 2009.

No agrupamento demais trabalhadores, essa queda não ocorreu, e entre 2007 e 2009, seu número elevou-se em $17 \%$.

Tabela 3. Pessoas formalmente ocupadas em empresas sucroalcooleiras na região Centro-Sul, de acordo com tipo de ocupação, final de 2007, 2008 e 2009

\begin{tabular}{|c|c|c|c|c|}
\hline Agrupamentos e Subdivisões & & 2007 & 2008 & 2009 \\
\hline \multirow{2}{*}{1 - Pessoas Ocupadas na Agricultura } & Valor & 323.917 & 326.630 & 302.936 \\
\hline & Índice & 100 & 101 & 94 \\
\hline \multirow{2}{*}{$\begin{array}{l}1.1 \text { - Trabalhadores Canavieiros não } \\
\text { Qualificados }\end{array}$} & Valor & 284.853 & 281.740 & 254.424 \\
\hline & Índice & 100 & 99 & 89 \\
\hline \multirow{2}{*}{$\begin{array}{l}1.2 \text { - Trabalhadores da Mecanização } \\
\text { Agrícola }\end{array}$} & Valor & 29.125 & 33.449 & 37.176 \\
\hline & Índice & 100 & 115 & 128 \\
\hline \multirow{2}{*}{$\begin{array}{l}1.3 \text { - Outras Pessoas Ocupadas na Agri- } \\
\text { cultura }\end{array}$} & Valor & 9.939 & 11.441 & 11.336 \\
\hline & Índice & 100 & 115 & 114 \\
\hline \multirow{2}{*}{$\begin{array}{l}\text { 2- Demais Pessoas Ocupadas em Empre- } \\
\text { sas Sucroalcooleiras }\end{array}$} & Valor & 174.645 & 193.010 & 204.872 \\
\hline & Índice & 100 & 111 & 117 \\
\hline \multirow{2}{*}{ Total nas Empresas Sucroalcooleiras } & Valor & 498.562 & 519.640 & 507.808 \\
\hline & Índice & 100 & 104 & 102 \\
\hline
\end{tabular}

Fonte: MTE (2010).

Já nas pessoas ocupadas na agricultura, observa-se praticamente uma estabilidade em seu número entre 2007 e 2008, e uma queda em 2009. Tal fato se deve à evolução do número de trabalhadores canavieiros não qualificados, que, entre 2007 e 2009 , apresentou redução de $11 \%$, revelando os efeitos, especialmente, da ampliação da área de cana-de-açúcar colhida mecanicamente. 
Por sua vez, o número de trabalhadores canavieiros na mecanização agrícola, contratados, em grande parte, para operarem as colhedoras de cana-de-açúcar, apresentou crescimento de $28 \%$ entre 2007 e 2009, embora em termos absolutos seu crescimento não tenha sido suficiente para compensar a diminuição dos trabalhadores canavieiros não qualificados.

\subsection{Sazonalidade da Ocupação dos Trabalhadores Canavieiros não Qualificados}

A Tabela 4 e a Figura 1 deixam evidenciado o grande nível de sazonalidade de empregos entre os trabalhadores canavieiros não qualificados. Em maio e junho, ápice da colheita da cana-de-açúcar, o número desses trabalhadores ultrapassa em $85 \%$ o constatado em janeiro, mês de entressafra, nos três anos analisados.

Quando se compara o ocorrido no mês de maior nível de ocupação (maio ou junho) com o de menor ocupação (dezembro) nos três anos considerados, percebe-se a ocorrência de diminuição na sazonalidade de emprego, não perceptível se a comparação é feita com o mês de janeiro.

Tabela 4. Número de trabalhadores canavieiros não qualificados, na região Centro-Sul, nos meses de 2007, 2008 e 2009

\begin{tabular}{ccccccc}
\hline \multirow{2}{*}{ Mês } & \multicolumn{2}{c}{2007} & \multicolumn{2}{c}{2008} & \multicolumn{2}{c}{2009} \\
\cline { 2 - 7 } & Número & Índice & Número & Índice & Número & Índice \\
\hline Janeiro & 188.655 & 100 & 181.321 & 100 & 162.079 & 100 \\
Fevereiro & 226.783 & 120 & 224.083 & 124 & 179.766 & 111 \\
Março & 261.534 & 139 & 258.377 & 142 & 235.253 & 145 \\
Abril & 317.520 & 168 & 321.541 & 177 & 289.928 & 179 \\
Maio & 350.207 & 186 & 338.679 & 187 & 300.649 & 185 \\
Junho & 347.157 & 184 & 336.889 & 186 & 299.122 & 185 \\
Julho & 335.112 & 178 & 327.626 & 181 & 292.649 & 181 \\
Agosto & 329.208 & 175 & 319.808 & 176 & 288.786 & 178 \\
Setembro & 324.702 & 172 & 315.662 & 174 & 286.939 & 177 \\
Outubro & 313.403 & 166 & 307.037 & 169 & 283.490 & 175 \\
Novembro & 271.169 & 144 & 286.307 & 158 & 273.336 & 169 \\
Dezembro & $\mathbf{1 5 2 . 7 8 8}$ & $\mathbf{8 1}$ & $\mathbf{1 6 3 . 5 5 5}$ & $\mathbf{9 0}$ & $\mathbf{1 6 1 . 0 9 6}$ & $\mathbf{9 9}$ \\
\hline
\end{tabular}

Fonte: MTE (2010). 
Figura 1. Evolução do índice do número de trabalhadores canavieiros não qualificados entre os meses de 2007, 2008 e 2009

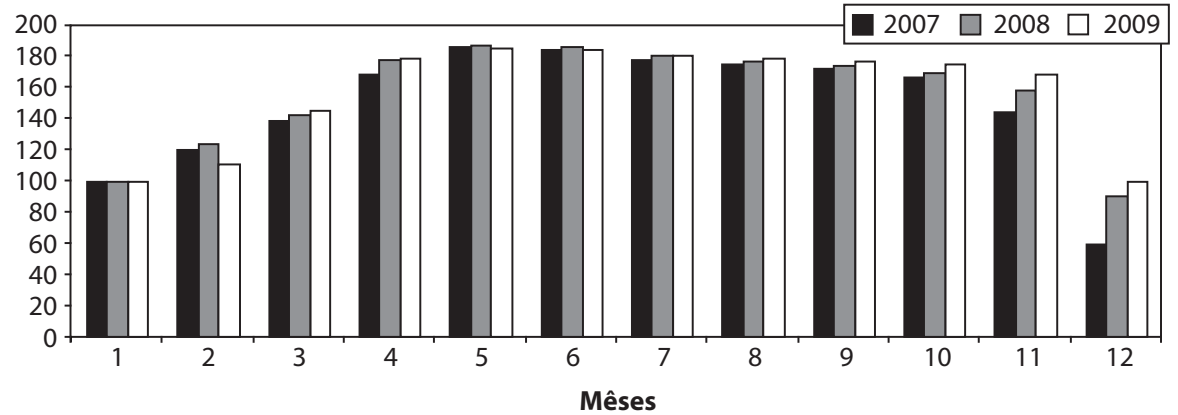

Fonte: MTE (2010).

São poucos anos de análise e a evidência, de fato, não é forte. Supondo que esteja ocorrendo uma redução na sazonalidade de emprego dos trabalhadores canavieiros não qualificados, ainda assim não há como atribuir este fato, com os dados disponíveis, ao aumento do nível de mecanização da colheita de cana-de-açúcar. Mesmo porque, em 2008 e 2009, por problemas climáticos e gerenciais, a colheita de cana-de-açúcar tendeu a se estender mais do que o normal, adentrando dezembro do ano e janeiro e fevereiro do ano seguinte em várias regiões ${ }^{8}$.

\subsection{Indicadores de Produtividade}

Na Tabela 5, percebe-se que a área colhida com cana-de-açúcar, bem como a produção de cana-de-açúcar, de açúcar e de etanol no Centro-Sul cresceram acima de $25 \%$ entre 2007 e 2009. Esses números são bem superiores ao aumento do total de ocupação sucroalcooleira, que foi de apenas $2 \%$, enquanto o número de trabalhadores canavieiros não qualificados caía em 11\% entre 2007 e 2009.

A partir dos dados da Tabela 5, foram calculados alguns índices de produtividade apresentados na Tabela 6. A produção de cana-de-açúcar (produto da atividade agrícola e insumo da atividade industrial) por pessoa ocupada nas empresas sucroalcooleiras cresceu 29\% entre 2007 e 2009, enquanto a produção de cana-de-açúcar por trabalhador canavieiro não qualificado crescia $47 \%$ no mesmo período. Por sua vez, a necessidade de trabalhadores canavieiros não qualificados por 1.000 hectares de cana-de-açúcar passou de 57 trabalhadores em 2007, para 40 trabalhadores em 2009, redução de $29 \%$.

8 Dados específicos para São Paulo apontam que a área de cana-de-açúcar "bisada", ou seja, que, diferente do inicialmente programado, ficou para ser colhida no ano seguinte, passou de 4,2\% do disponível para colheita na safra 2007/08, para $11,6 \% \mathrm{em}$ 2008/09, alcançando 16,8\% em 2009/10 (AGUIAR et al., 2010). 
Tabela 5. Indicadores de produção e de ocupação sucroalcooleiras, Centro-Sul, 2007 a 2009

\begin{tabular}{lccc}
\hline \multicolumn{1}{c}{ Indicadores } & $\mathbf{2 0 0 7}$ & $\mathbf{2 0 0 8}$ & $\mathbf{2 0 0 9}$ \\
\hline Área Colhida (em mil hectares) & $5.020,0$ & $5.952,3$ & $6.309,8$ \\
Índice & 100 & 119 & 126 \\
Produção de Cana (em mil toneladas) & $413.459,8$ & $502.154,1$ & $542.844,8$ \\
Índice & 100 & 121 & 131 \\
Produção de Açúcar (em mil toneladas) & $26.421,2$ & $27.074,6$ & $33.741,0$ \\
Índice & 100 & 102 & 128 \\
Produção de Etanol (em milhões de litros) & $20.789,4$ & $24.327,5$ & $26.292,9$ \\
Índice & 100 & 117 & 126 \\
Total Ocupação Sucroalcooleiro & 498.562 & 519.640 & 507.808 \\
Índice & 100 & 104 & 102 \\
Trabalhadores Canavieiros ñ Qualificados & 284.853 & 281.740 & 254.424 \\
Índice & $\mathbf{1 0 0}$ & $\mathbf{9 9}$ & $\mathbf{8 9}$ \\
\hline
\end{tabular}

Fonte: Conab (2010), MTE (2010).

Tabela 6. Indicadores de produtividade sucroalcooleiros, Centro-Sul, 2007 a 2009

\begin{tabular}{lccc}
\hline \multicolumn{1}{c}{ Indicador } & $\mathbf{2 0 0 7}$ & $\mathbf{2 0 0 8}$ & $\mathbf{2 0 0 9}$ \\
\hline Produção de Cana/Total Ocupação & 829 & 966 & 1.069 \\
Índice & 100 & 117 & 129 \\
Produção de Cana/Trab. Can. não Qual. & 1.451 & 1782 & 2134 \\
Índice & 100 & 123 & 147 \\
Trab. Can. ñ Qual./1.000 ha de cana & 57 & 47 & 40 \\
Índice & $\mathbf{1 0 0}$ & $\mathbf{8 3}$ & $\mathbf{7 1}$ \\
\hline
\end{tabular}

Fonte: Conab (2010), MTE (2010).

\section{Considerações Finais}

Entre 2007 e 2009, observou-se que no Centro-Sul do Brasil os indicadores de produção sucroalcooleiro e de área canavieira apresentaram expansão bem acima do número de pessoas formalmente ocupadas por empresas sucroalcooleiras. Tal fato reflete importantes ganhos de produtividade, mais significativos no caso dos trabalhadores canavieiros não qualificados.

Enquanto outras categorias de ocupação registraram crescimento no período de análise, o número de trabalhadores canavieiros não qualificados apresentou 
significativa redução. Uma evidente alteração na composição da ocupação agrícola sucroalcooleira vem sendo observada, com perda de importância dos trabalhadores não qualificados, dedicados especialmente ao corte da cana-de-açúcar, e crescimento relativo de ocupações que exigem maior qualificação profissional, como a dos operadores de máquina.

A sazonalidade de emprego dos trabalhadores canavieiros não qualificados, embora possa ter registrado um pequeno decréscimo no período de análise, mantém-se elevada, com o número de trabalhadores contratados no mês de maior nível de ocupação superando em $85 \%$ aquele do mês de menor nível de ocupação.

Pode-se imaginar que parte dos trabalhadores canavieiros não qualificados que estão sendo dispensados de atividades como a do corte de cana-de-açúcar seja absorvida em outras funções pelas próprias empresas sucroalcooleiras. Neste sentido, tem-se observado ações empresariais procurando qualificar os trabalhadores agrícolas para o exercício de novas funções, como a de operadores de máquinas agrícolas.

Contudo, em termos de saldo, o número de trabalhadores canavieiros não qualificados demitidos é bem maior que o número de trabalhadores na mecanização agrícola contratados por empresas sucroalcooleiras. Há, portanto, a necessidade de o poder público, inclusive dos municípios canavieiros, avaliar melhor a situação local e pensar em desenvolver programas de recolocação e requalificação profissional.

Acrescente-se que parte dos trabalhadores canavieiros não qualificados, que ora estão sendo demitidos, são migrantes sazonais, provenientes de estados do Nordeste. Nesse sentido, há de se desenvolver ações públicas também nestas regióes, inclusive aquelas voltadas para o fortalecimento dos agricultores familiares, que constituem parcela considerável dos migrantes citados.

\section{Referências Bibliográficas}

AGUIAR, D. A. et al. Monitoramento do modo de colheita da cana-de-açúcar no Estado de São Paulo - ano safra 2009/2010. INPE/MCT -16685-RPQ/851. São José dos Campos (SP), 2010. 154 p.

BACCARIN, J. G.; BARA, J. G. Boletim Ocupação Formal Sucroalcooleira em São Paulo. Número 7, anexo, outubro de 2009. Disponível em www.fcav.unesp.br/ baccarin.

BACCARIN, J. G.; GEBARA, J. J. Intensificación del ritmo y reducción de los puestos de trabajo de los trabajadores cañeros en el Estado de São Paulo, Brasil. In VI Congreso de la Asociación Latinoamericana de Sociología del Trabajo (ALAST). 2010, Cidade do México (México), 20 a 23 de abril de 2010. 
CONAB. Perfil do setor de açúcar e álcool no Brasil - situação observada em novembro de 2007 a abril de 2008. Brasília: CONAB, 2008. 75 p.

CONAB (Companhia Nacional de Abastecimento). Central de Informações Agropecuárias. Disponível em www.conab.gov.br. Acesso em julho de 2010.

FREDO, C. E.; OTANI, M. N.; VICENTE, M. C. M.; BAPTISTELLA, C. da S. L.; VEIGA, J. E. R. Índice de mecanização na colheita da cana-de-açúcar no estado de São Paulo e nas regiões produtoras paulistas, junho de 2007. Disponível em www.iea. sp.gov.br. Acesso em março de 2008.

MAPA (Ministério da Agricultura, Pecuária e Abastecimento). Anuário estatístico da agroenergia. Brasília: MAPA/ACS, 2009. 160 p.

MAPA. Disponível em http://www.agricultura.gov.br/pls/portal/docs/PAGE/ MAPA/SERVICOS/USINAS_DESTILARIAS/USINAS_CADASTRADAS/UPS_2506-10_0. PDF. Acesso em julho de 2010.

MTE (Ministério do Trabalho e Emprego). Classificação Brasileira de Ocupações. Disponível em www.mtecbo.gov.br. Acesso em novembro de 2009.

MTE. Programa de Disseminação de Estatística do Trabalho. Disponível em www. mte.gov.br. Acesso em julho de 2010.

MORAES, M. A. F. D. de. Mercado de trabalho do setor de açúcar e álcool: desafios atuais e perspectivas futuras. Workshop Mercado de Trabalho do Setor Sucroalcooleiro - Desafios e Perspectivas Futuras, 2003, Piracicaba. Piracicaba: ESALQ/USP, 2004, 11 p.

PAES, L. A. D. Áreas de expansão do cultivo da cana. In: MACEDO, I. de C. (Org.). A energia da cana-de-açúcar - doze estudos sobre a agroindústria da canade-açúcar no Brasil e sua sustentabilidade. São Paulo: ÚNICA, 2007. P. 125-133. (2⿳亠口冋. Edição). 